\title{
VIRGILIO EN LA MUERTE DE CELESTINA
}

\author{
Manuel Garcta Plaza
}

Lo que sigue es sólo una brevísima propuesta sobre las condiciones de la recepción de uno de los textos clásicos más influyentes en el mundo de Rojas y de cómo la Celestina es una buena muestra de asimilación y reelaboración literaria.

Quienes han estudiado la obra de Rojas desde este punto de vista han señalado los préstamos textuales o las referencias históricas tomadas de la Eneida de Virgilio. Castro Guisasola recuerda la cita literal de IV, 13 (Degeneres animos timor arguit) en unas palabras de Pleberio contenidas en el acto $\mathrm{X}$ («a los flacos coraçones el dolor los arguye»). "Es muy posible - añade - que la 'sacrílega hambre de oro' de que habla Elicia en el aucto XV añadido, sea reflejo del celebrado hemistiquio: auri sacra fames" de III, 57. El proverbio audentes fortuna iuvat que se lee en X, 284, figura en el aucto I («mas di, como Marón, que la fortuna ayuda a los osados»). ${ }^{1}$ María Rosa Lida amplió las citas literarias a unas palabras de Elicia en el aucto IX ("ni gozan deleyte ni conocen los dulces premios del amor"), procedentes de Eneida, IV, 33 (nec dulcis natos, Veneris nec proemia noris?). Completa, además, los posibles ecos de III, 57, que ya señalaba Castro Guisasola, con otros lugares de Celestina, aunque sugiere que hayan podido arribar por intermedio de Juan de Mena. ${ }^{2}$

Otro modo de presencia virgiliana es cuando se pone en boca de los personajes argumentos, historias o ejemplos tomados de historias narradas por Virgilio, como la causa de los amores de Dido y Eneas (Eneida I, 661 y sigs.) o el papel de un hombre solo, Sinón, en la toma de la ciudad (II, 195). ${ }^{3}$ Es evidente que las circunstancias de la muerte de Melibea tienen estrecha relación, como señaló $\mathrm{M}$. R. Lida, con IV, 474 y sigs. Precisamente, Peter Russell modera la importancia de la relación entre las dos muertes de Dido y Melibea y aboga por no "conceder una influencia exagerada a estas reminiscencias literarias"; y añade: "El deseo de una amante afligida de reunirse mediante el suicidio con el amante inesperadamente muerto representa una característica inherente a la psicología del amor humano."4

Aunqué esto es razonabilísimo, una reminiscencia concreta y famosa-en este caso, la muerte de Dido y sus circunstancias - no puede anularse en virtud de lo genérico del caso (suicidio de la amante abandonada), sobre todo porque el origen 
de estas reminiscencias está en una obra que, aparte dejar rastros concretos en otras secciones de Celestina, formaba parte del curriculum de estudios latinos de un bachiller salmantino; y todos sabemos hasta qué punto la asimilación escolar de los auctores durante la Edad Media era a veces capilar y a veces arterial. El tipo de estudio privilegiaba la memorización literal de los textos para la fijación de las reglas gramaticales, cuanto para su vertido en las prácticas escritas u orales de los mismos estudiantes. Pero, simultáneamente, se producía una asimilación de situaciones, caracteres, modelos, etc., que a veces pueden ser utilizados en el espacio de la creación literaria o apenas se reconocen como mera reminiscencia.

Así, muchos de los recuerdos virgilianos espigados por Courcelle en la tradición patrística y cristiana en general son resultado de esta asimilación natural que, aunque en ocasiones está lejos de la letra, son resultado de una profunda y consciente, aunque no siempre, asimilación, que, aun manifestándose apenas por la presencia de tal palabra o breve fase de Virgilio-en autores que escriben en latíntal recuerdo de situaciones o de caracteres, implica sin embargo un reconocimiento de autoridad, es un modo de ornamento e, incluso, puede llegar hasta representar una actitud filosófica o ética. ${ }^{5}$

En una obra como la de Rojas, en la que el centoneo de citas literales es a discreción y muy acorde con un modo de composición aprendido que no exige la consapevolezza critica de la asimilación del contexto de la cita; en una obra en la que las autoridades forman ringlera en los repertorios con los que se empedraban los discursos en general y en particular los de Celestina, ${ }^{6}$ la reminiscencia sorprendente de tal o cual pasaje, tal carácter de un personaje o tal situación, quizá pueda ser más significativa de consciencia poética que cualquier otra cita literal.

Propongo, así, que en la anti-heroica y vergonzosa muerte de Celestina hay una reminiscencia leve consciente de otra muerte honrada y heroica, la de Príamo tal como se recuerda en Eneida II, 530 y sigs. Este segundo libro es, por contener una de las versiones autorizadas de la caída de Troya, uno de los más populares de la Eneida y fue, además de leidísimo, estudiado en los ambientes escolares. Narra Virgilio que Príamo, refugiado con las mujeres en el altar de los Penates, ve cómo muere su hijo Polites por la violencia de Pirro, hijo de Aquiles. Antes de lanzarle el venablo, Príamo se encara con él y, después de desearle el castigo de los dioses, le recuerda que no era ése el trato que le dio su padre: "at non ille, satus quo te mentiris, Achilles | talis in hoste fuit Priamo." Pirro, fanfarrón, le contesta: «[...] referes ergo haec et nuntius ibis | Pelidae genitoris. ${ }^{7}$

En el aucto XII, después de reclamar la parte que creen corresponderles de los regalos que Calisto daba a Celestina, Pármeno y Sempronio oyen cómo ésta se excusa para no partir con ellos achacando la pérdida de la cadenilla; insistiendo éstos, les promete continuar facilitándoles muchachas; al fin, deja las excusas y se encara con los criados. A Sempronio lo amenaza con la justicia, y a Pármeno le dice que de 
poco servirá que él sepa sus secretos en estos términos: "E tú, Pármeno, ¿piensas que soy tu cativa, por saber mis secretos y mi passada vida y los casos que nos acaescieron a mí y a la desdichada de tu madre? ¡Y aun assí me tratava ella cuando Dios queria!” Pármeno le contesta: "No me hinches las narizes con estas memorias; si no, embiarte he con nuevas a ella, donde mejor te puedas quexar" (483). Estas palabras de Pármeno vienen a concretarse más abajo en boca de Sempronio: “¿Esperá, doña hechizera, que yo te haré yr al infierno con cartas!" (485).

El lector de Celestina y de la Eneida sabe perfectamente la distancia de las dos situaciones, pero creo que no se pueden negar en el entramado de la acción y las palabras de los protagonistas indicios de cercanía: las dos víctimas recuerdan un trato mejor de los progenitores de los verdugos; éstos reaccionan con la amenaza o promesa de que serán Príamo y la propia Celestina los que van a poder quejarse en el más allá a sus padres. Esta amenaza queda, en la Celestina, remachada por Sempronio, con lo que, desde la perspectiva de la lectura de la Eneida, apreciaríamos el interés de Rojas por geminar el lejano modelo de Pirro.

Donato apreciaba en la obra de Terencio el óptimo efecto cómico de poner en boca de criados de baja estofa palabras sentenciosas; los comentadores de Juvenal destacaban los efectos de extraer del poema heroico por excelencia el jugo antiheroico. Rojas emboca la reminiscencia de una situación trágica para caracterizar $e$ converso la trágica anti-heroica y, de paso, modificar la esencia o las virtualidades de una lectura consagrada. No sabría dictaminar sobre el índice de consciencia que Rojas quiere que el lector tenga en este proceso. Podría decirse que, si hubiera querido que advirtiéramos su uso, quizá nos daría aún más referencias- no sé si es desdeñable o no que en boca de Sempronio se ponga en el acmé de la acción el recuerdo de Eneida, III, 57, como señaló María Rosa Lida-, pero la eficacia de la poética de Celestina muchas veces estriba en la misma técnica de la alusión que comparte con otros buenos escritores medievales, como Dante, Petrarca o Jorge Manrique, los cuales incorporaban sus lecturas arterialmente, en profundidad, y no capilarmente, en lo exterior. Confío que esto sea, en efecto, un resultado de esa técnica de la alusión y no de la ilusión del autor de las presentes líneas.

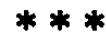

\section{Notas}

'F. Castro Guisasola [1924], Observaciones sobre las fuentes literarias de La Celestina', reimpresión (Madrid: CSIC, 1973), 64.

${ }^{2}$ La originalidad artistica de La Celestina' (Buenos Aires: EUDEBA, 1970²), 339.

${ }^{3}$ Castro Guisasola, Observaciones, 65.

${ }^{4}$ En su edición de Celestina (Madrid: Cátedra, 1991), 589n44.

${ }^{5}$ Ver Pierre Courcelle, Lecteurs païens et lecteurs chrétiens de l'Enéide, I. Les témoignages littéraires, Paris: Institut de France, 1984. 
${ }^{6}$ Véase Peter Russell, «Discordia universal: La Celestina como Floresta de philósophon», Insula, núm. 497 (1988), 1-3. Aparte las dependencias de recopilaciones como los índices de los Opera de Petrarca estudiados por Deyermond, tenemos ahora seguridad del uso de una de esas colecciones de sentencias, Parvi flores o Auctoritates Aristotelis (Iñigo Ruiz Arzallus, «El mundo intelectual del antiguo auctor. las Auctoritates Aristotelis en la Celestina primitivas, Boletin de la R Academia Española 76 [1996]: 265-284).

${ }^{7}$ En una tradición antigua, la parte que más me interesa se propone así: “e por çierto tú non eres fijo de aquel que dizes mintrosamente Acchiles, el qual non non fue tal contra mi" (Enrique de Villena, Traducción y glosa de la 'Eneida'. Libro segundo, ed. P. M. Cátedra [Salamanca: Diputación, 1989], 235).

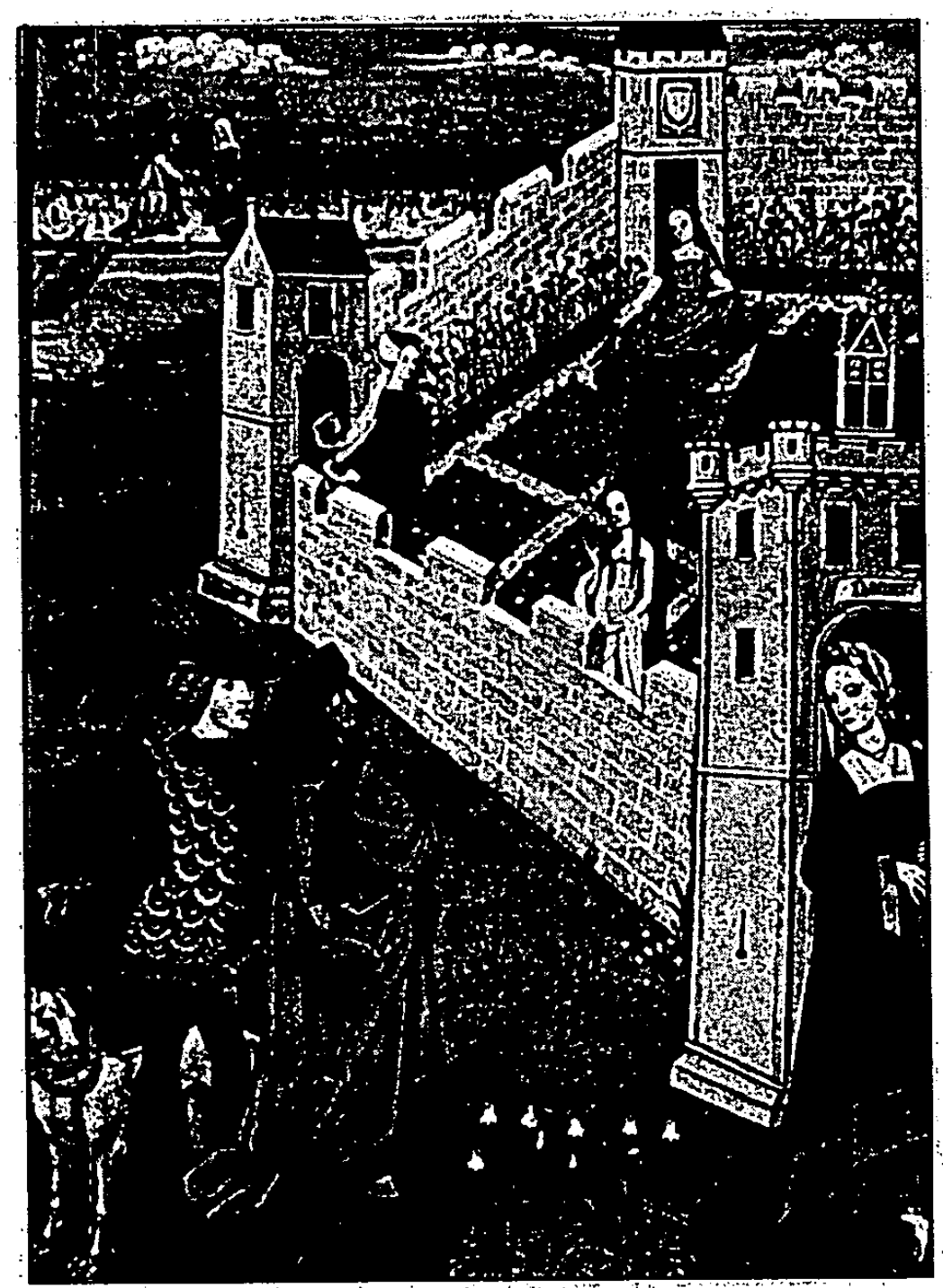

Portada. Madrid: Alianza, 1998. 